\title{
Incorporating Cold Cap Behavior in a Joule-heated Waste Glass Melter Model
}

Varija Agarwal

Donna P. Guillen

August 2013

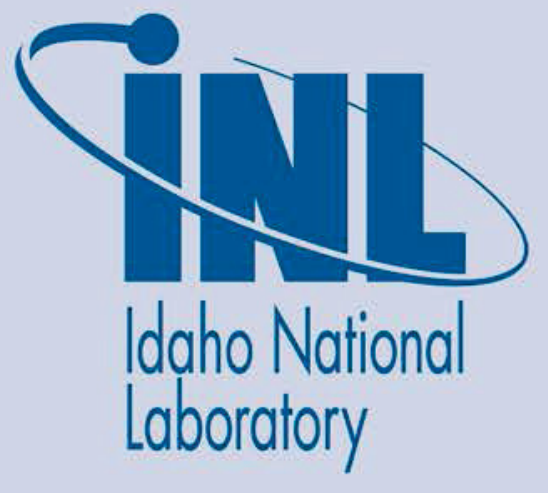

The INL is a U.S. Department of Energy National Laboratory operated by Battelle Energy Alliance 


\section{DISCLAIMER}

This information was prepared as an account of work sponsored by an agency of the U.S. Government. Neither the U.S. Government nor any agency thereof, nor any of their employees, makes any warranty, expressed or implied, or assumes any legal liability or responsibility for the accuracy, completeness, or usefulness, of any information, apparatus, product, or process disclosed, or represents that its use would not infringe privately owned rights. References herein to any specific commercial product, process, or service by trade name, trade mark, manufacturer, or otherwise, does not necessarily constitute or imply its endorsement, recommendation, or favoring by the U.S. Government or any agency thereof. The views and opinions of authors expressed herein do not necessarily state or reflect those of the U.S. Government or any agency thereof. 


\title{
Incorporating Cold Cap Behavior in a Joule-heated Waste Glass Melter Model
}

\author{
Varija Agarwal, Georgia Institute of Technology, Atlanta, GA \\ Donna P. Guillen, Idaho National Laboratory, Idaho Falls, ID
}

August 2013

Idaho National Laboratory Idaho Falls, Idaho 83415

http://www.inl.gov

Prepared for the

U.S. Department of Energy

Assistant Secretary for Environmental Management

Under DOE Idaho Operations Office

Contract DE-AC07-05ID14517 



\section{SUMMARY}

In this paper, an overview of Joule-heated waste glass melters used in the vitrification of high level waste (HLW) is presented, with a focus on the cold cap region. This region, in which feed-to-glass conversion reactions occur, is critical in determining the melting properties of any given glass melter. An existing 1D computer model of the cold cap, implemented in MATLAB, is described in detail. This model is a standalone model that calculates cold cap properties based on boundary conditions at the top and bottom of the cold cap. Efforts to couple this cold cap model with a 3D STAR-CCM+ model of a Joule-heated melter are then described. The coupling is being implemented in ModelCenter, a software integration tool. The ultimate goal of this model is to guide the specification of melter parameters that optimize glass quality and production rate. 


\section{ACKNOWLEDGEMENTS}

The authors gratefully acknowledge that this work was supported by the Department of Energy's Waste Treatment \& Immobilization Plant Federal Project Office under the direction of Dr. Albert A. Kruger. This work was also supported in part by the U.S. Department of Energy, Office of Science, Office of Workforce Development for Teachers and Scientists (WDTS) under the Science Undergraduate Laboratory Internship (SULI) program. The authors acknowledge Brant Peery and Sam Alessi at the Idaho National Laboratory for invaluable guidance on the use of ModelCenter. Girish Bhandari of CD-adapco is also thanked for support in the implementation of the Simulink coupling and for providing the artery model (developed by Stefan Holst of CD-adapco) as a coupling example. Eric Volpenhein of CD-adapco graciously provided STAR$\mathrm{CCM}+$ licenses for the students' use. Additionally, April Schneider (Cornell University) provided support in the coupling and was primarily responsible for the development of the melter model. 


\section{CONTENTS}

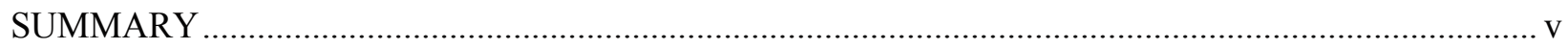

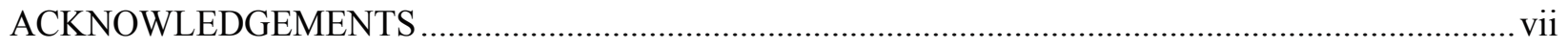

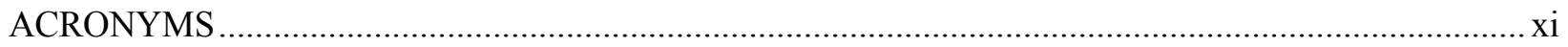

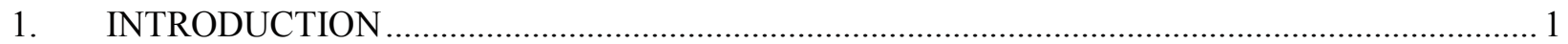

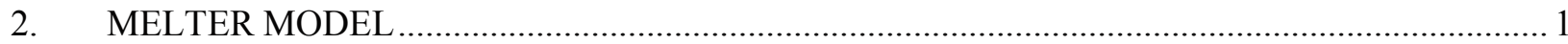

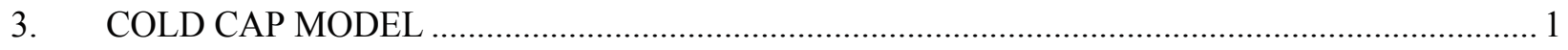

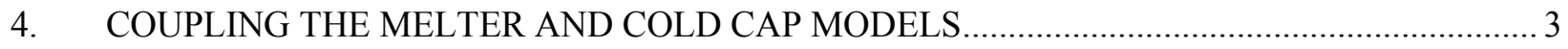

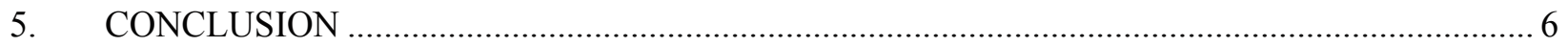

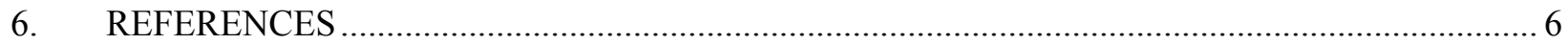

\section{FIGURES}

Figure 1. 3D model of Joule heated waste glass melter created in STAR-CCM+ ..................................2

Figure 2. Depiction of cold cap structure and heat transfers.................................................................. 3

Figure 3. Basic version of coupled ModelCenter model...................................................................... 4

Figure 4. Outline of data exchange that occurs in coupled model. .........................................................5 


\section{ACRONYMS}

GUI graphical user interface

HLW high-level waste

LLW low-level waste

ODE ordinary differential equation

SULI Science Undergraduate Laboratory Internship

TGA thermogravimetric analysis

WDTS Workforce Development for Teachers and Scientists

WTP Waste Treatment and Immobilization Plant 


\section{Incorporating Cold Cap Behavior in a Joule-heated Waste Glass Melter Model}

\section{INTRODUCTION}

Waste from the legacy of more than 45 years of nuclear materials production for national defense purposes has resulted in tremendous cleanup challenges. At the Hanford site in southeastern Washington, 177 underground storage tanks containing approximately 55 million gallons of nuclear waste ${ }^{1}$ pose a risk to the surrounding environment. The Department of Energy's goal is to safely remove the liquid waste from the tanks, separate the low-level waste (LLW) from the high-level waste (HLW) and treat the materials into a solid form that can be safely disposed of. Vitrification is the preferred method of treatment wherein radioactive waste is melted with glass forming materials and then poured into a steel cask, in which the mixture cools into a stable glass form for final disposal. ${ }^{1}$ At the heart of the vitrification process is the Joule-heated melter, into which slurry feed is charged. During the melting process, a molten glass region forms towards the bottom of the melter, and a thin region called a cold cap forms on top of the molten glass. The cold cap is perhaps the most significant region of the melter, as it is the region in which feed-to-glass conversion occurs. Because of its complex nature, however, the cold cap can be difficult to model, and it has often been treated inadequately in melter simulations. ${ }^{2}$ Thus, in this project, a 3D model of an HLW Joule-heated melter is being developed that accurately represents the cold cap. The model couples an existing 1D MATLAB model of the cold cap with a 3D STAR-CCM+ model of the melter. The coupling is being performed using ModelCenter, a software integration tool that can be used to create simulations of complex, multi-part systems. It is foreseeable that this type of coupled model will be able to make accurate predictions of melting properties under varying conditions, thus allowing for vitrification operations such as the Hanford Waste Treatment and Immobilization Plant (WTP) to maximize their operating efficiency.

\section{MELTER MODEL}

The melter model used in the coupled simulation has been created using STAR-CCM+, a powerful computational fluid dynamics tool. The melter, shown in Figure 1, consists of several regions. At the top is an inlet through which melter feed, comprising about $50 \%$ water, is charged. Below this inlet is an air-filled plenum space which leads to the cold cap, a foamy region where complex, transformative reactions occur. The cold cap rests upon a pool of molten glass, which then exits through an outlet at the bottom of the melter. In the molten glass region, electrodes are situated on the walls of the melter; these electrodes provide the electrical heating which drives the melting process. Other significant parts of the melter are the bubble injector and the off-gas port. The bubble injector forces bubbles into the molten glass, providing forced convection and an increase in the melting rate. The off-gas port is an outlet at the top of the melter through which bubbles generated in the melting process can escape.

The STAR-CCM+ melter model is capable of solving for the temperature, velocity and electric fields inside the melter. This model, however, does not incorporate the physicochemical processes occurring in cold cap region. The cold cap appears as a cavity in the model, and its properties are left to be determined by the numerical MATLAB model described in the next section.

\section{COLD CAP MODEL}

When melter feed, also referred to as glass batch, is poured into a melter, a batch layer tends to form on top of the molten glass. This layer, called the cold cap, covers approximately $95 \%$ of the molten glass surface $^{3}$ and comprises two main regions: the open porosity layer and the foam layer. ${ }^{2}$ In the open porosity layer, gases that have evolved in conversion reactions escape upwards relatively easily. The same is not true of the foam layer, which, as depicted in Figure 2, has three layers: the primary foam layer, the cavity layer and the secondary foam layer. In the primary foam layer, the high viscosity of the glass melt 
does not allow bubbles to escape upwards. Instead, bubbles sink downwards into the cavity layer, where they coalesce into larger bubbles, or cavities. These cavities are thought to move horizontally to the edges of the cold cap, where they escape into the plenum space through vent holes. Below the cavity layer, the secondary foam layer consists of bubbles created from redox reactions occurring in the molten glass below. Due to the extremely high viscosity of the glass in this layer, secondary foam bubbles are relatively immobile.

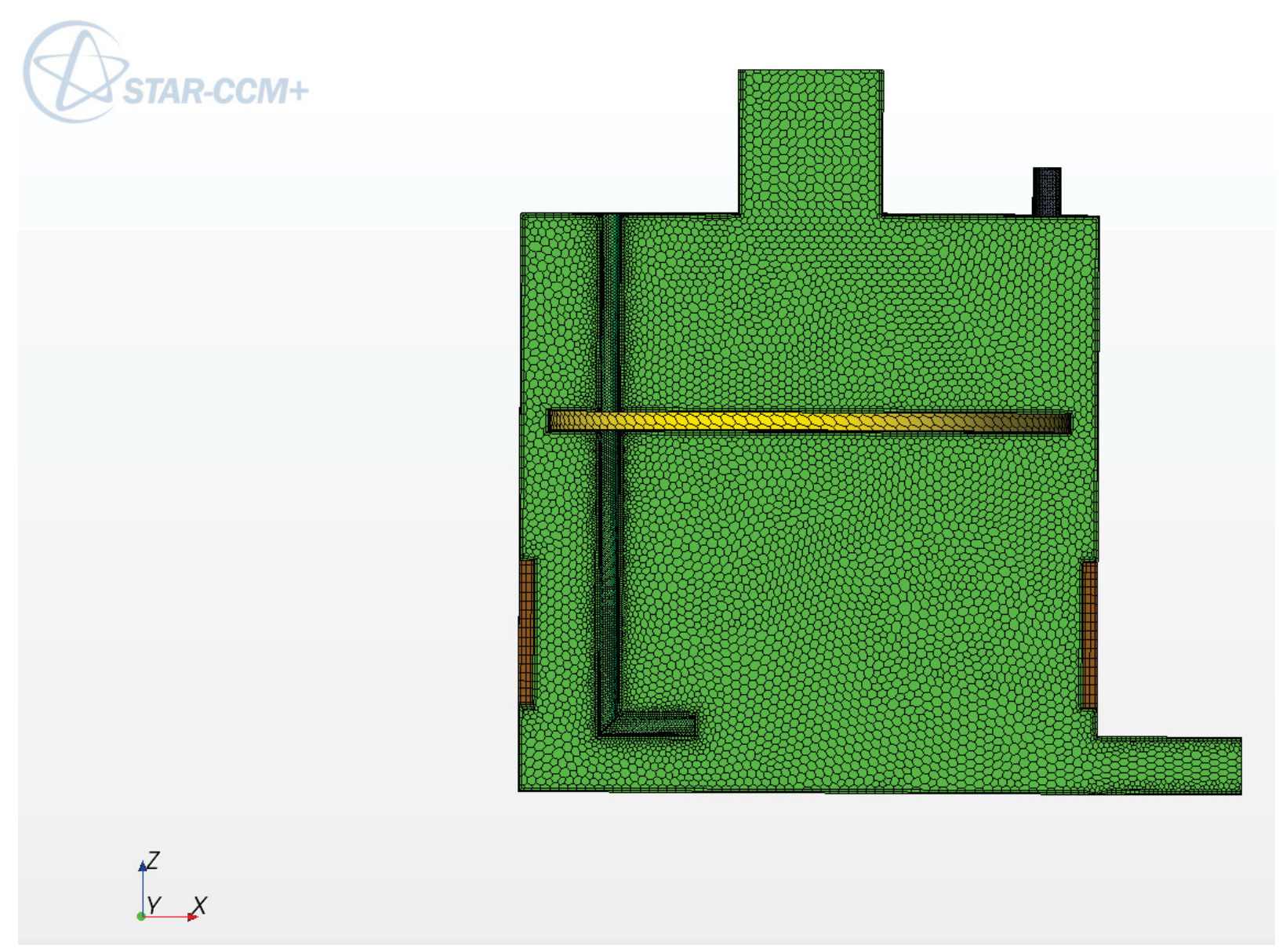

Figure 1. 3D model of Joule heated waste glass melter created in STAR-CCM+.

The cold cap is the region in which the melter feed is converted into molten glass. The structure of the cold cap is thus highly significant in determining melting properties. ${ }^{2}$ As shown in Figure 2, there is heat transfer, labeled QB in the figure, from the molten glass to the cold cap bottom. This heat is transferred through the foam layer to evaporate water from the slurry at the top of the cold cap and also to melt the resulting dry feed. Additionally, as the cold cap does not cover the entire molten glass surface, there is heat transfer directly from the molten glass to the plenum space beyond the edges of the cold cap. This heat transfer, labeled QU in Figure 2, also aids in the evaporation of water from the slurry. In order to properly predict melting properties, any model of the cold cap must accurately incorporate these boundary heat transfers.

In the MATLAB model developed by Pokorny and $\mathrm{Hrma}^{2}$, the temperatures at the top and bottom of the cold cap are initially assumed to be $100^{\circ} \mathrm{C}$ and $1100^{\circ} \mathrm{C}$, respectively. A temperature profile is then created for the cold cap based on these boundary temperatures in the form of a matrix. Material properties, namely heat conductivities, heat capacities and spatial density, are then calculated based on this temperature profile, as these properties are dependent on temperature. These material properties are 
subsequently used to calculate heat and material flows in the cold cap, which are then used to solve the energy balance ODE for the cold cap using a built-in ODE solver in MATLAB. The solution of the energy balance ODE yields the final temperature profile for the cold cap. The physical running time for the model can easily be controlled from within the MATLAB code.

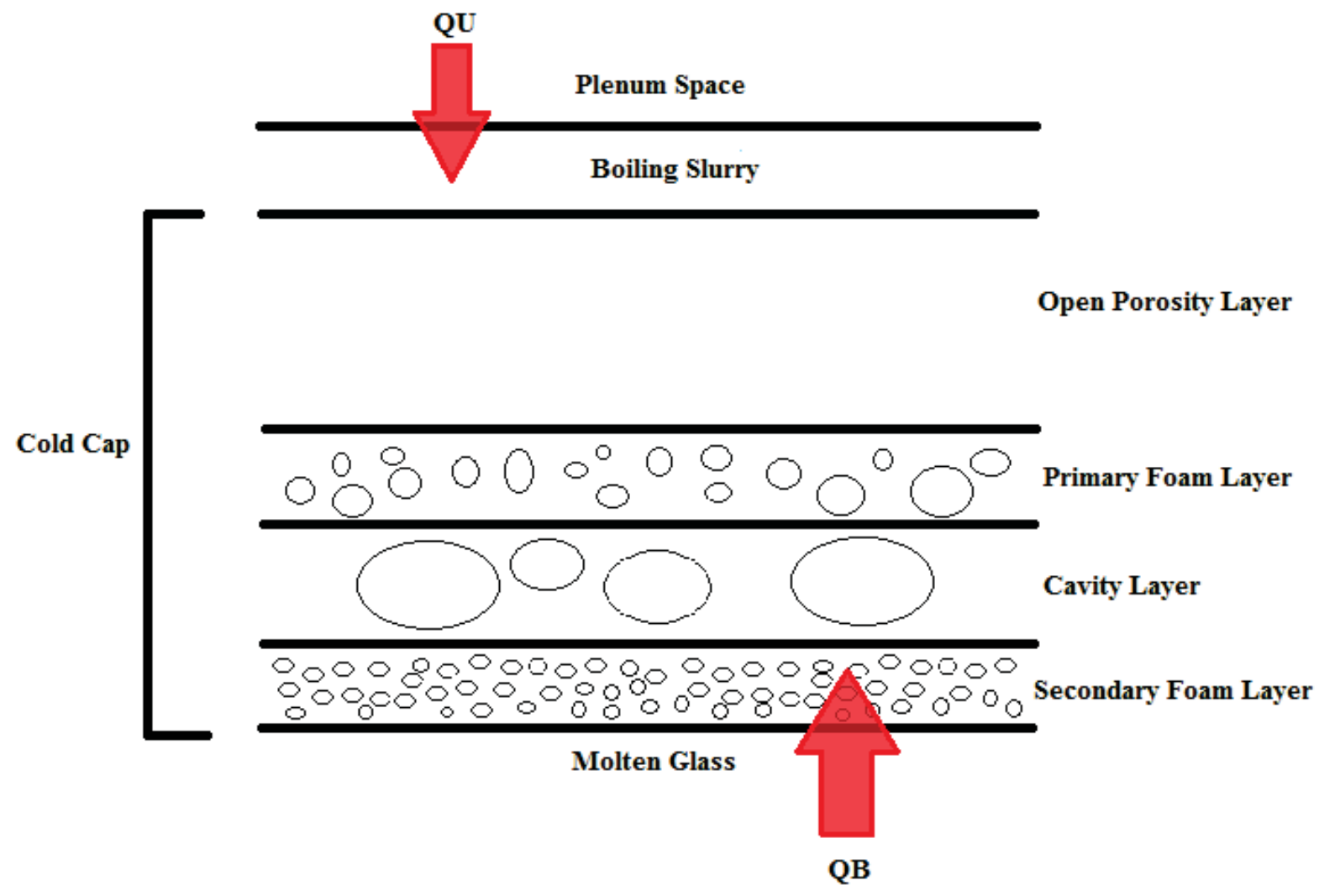

Figure 2. Depiction of cold cap structure and heat transfers.

The melting process itself is incorporated into the cold cap model by calculating the degree of conversion of the melter feed using data from thermogravimetric analysis (TGA). ${ }^{4}$ Because literally thousands of reactions take place in the feed-to-glass conversion, for analytical simplicity, the multiple gas-evolving reactions that occur in the cold cap are lumped together, and the reaction kinetics for the batch is studied using experimental data. The degree of conversion is then used to obtain solid and gaseous mass flows through the cold cap.

It is important to note that this MATLAB model is a standalone model - it makes assumptions for the boundary conditions, namely the temperatures and heat transfers at the top and bottom of the cold cap. In the cohesive simulation which couples the melter and cold cap models, boundary conditions for the cold cap are to be obtained from the model of the melter.

\section{COUPLING THE MELTER AND COLD CAP MODELS}

The STAR-CCM+ model of the glass melter does not take into account the cold cap region, and the MATLAB model of the cold cap is a standalone model that does not incorporate interactions with the rest of the melter. Additionally, the extremely complex properties of the cold cap, which result from its foamy structure and the multifarious reactions taking place in the region, make modeling the cold cap in STAR-CCM+ unrealistic, as STAR-CCM+ is useful for modeling systems with well-defined properties. Therefore, in order to create a cohesive, more accurate simulation of a glass melter, the STAR-CCM+ model of the melter must be coupled with the MATLAB model of the cold cap. 
This coupling, shown in Figure 3, is being implemented in ModelCenter 10.2, which allows for the integration of various models into a single simulation. ModelCenter offers a plug-in for MATLAB, greatly facilitating the creation of a ModelCenter component for the cold cap model. The cold cap component makes a call to the MATLAB code, which is executed externally in a MATLAB engine. Though a similar plug-in is not available for STAR-CCM+, a general script wrapping utility, QuickWrap, has been used to create a component for the melter model. This utility requires a Java macro from the STAR-CCM+ simulation; this macro is run in batch mode every time the melter component runs. QuickWrap also makes use of output files from STAR-CCM+, which are parsed at user-specified delimiters to extract the values that are to be sent to MATLAB.

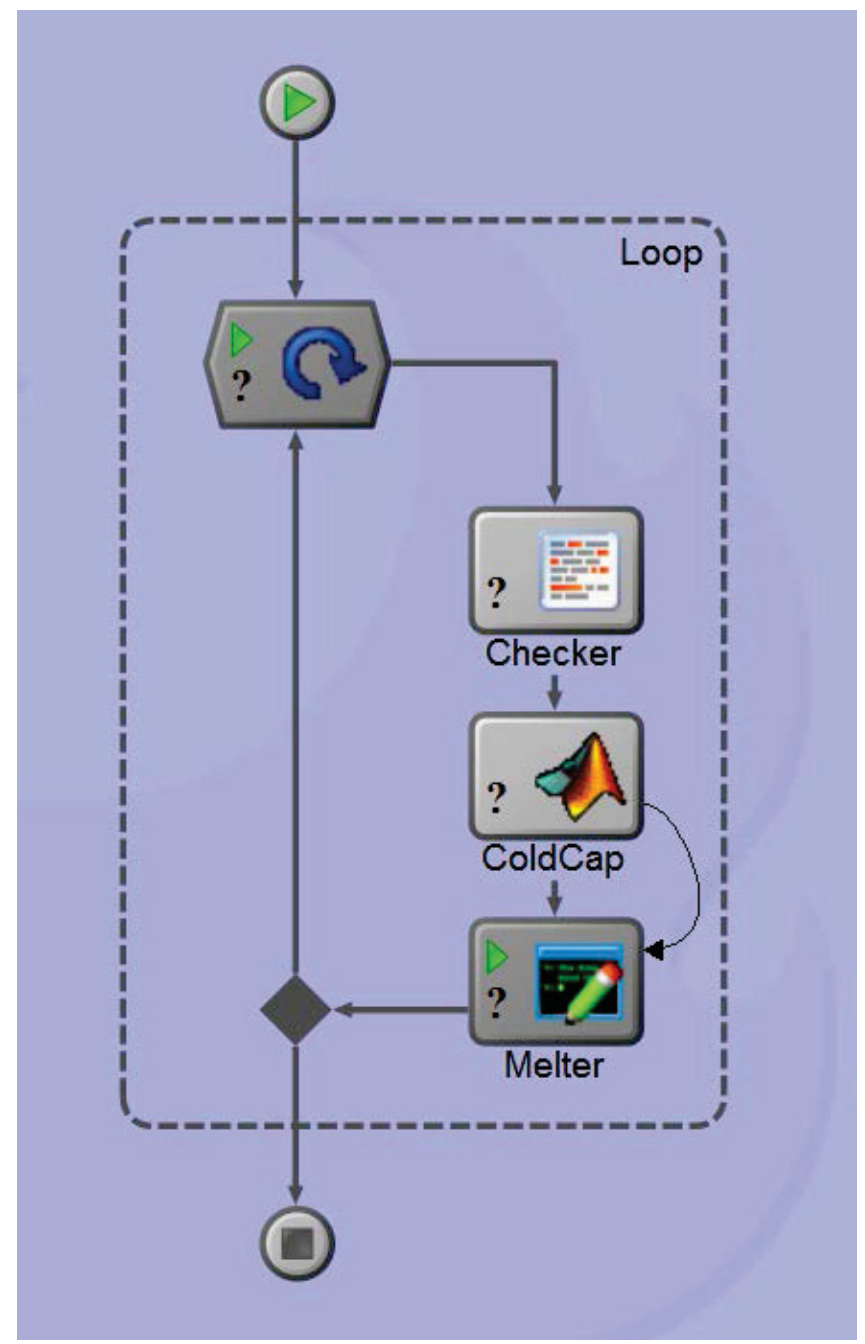

Figure 3. Basic version of coupled ModelCenter model.

The actual coupling is performed by connecting the MATLAB and STAR-CCM+ models via a loop component. The outputs of MATLAB have been directly connected to the inputs of STAR-CCM+, and the outputs of STAR-CCM+ flow to the inputs of MATLAB in the form of loop feedback variables. This data exchange is depicted in Figure 4. The MATLAB component takes in TB, the temperature at the bottom of the cold cap and QU, the heat transfer from the plenum space to the slurry. The MATLAB component then returns QB, the heat transfer from the molten glass to the bottom of the cold cap, TT, the temperature at the top of the cold cap, MGAS, the mass flux of the gases emerging from the top of the 
cold cap and MGLASS, the mass flux of the molten glass exiting the bottom of the cold cap. The STAR-CCM+ component takes in QB, TT, MGAS and MGLASS and returns TB and QU. Therefore, a cyclical relationship exists between the MATLAB and STAR-CCM+ models, as the inputs and outputs of each model depend on the other. A script component, written in VBScript, is used in the loop to perform bounds checking of the variables entering MATLAB from STAR-CCM+. This component is also used to determine how many times the loop component runs. The number of iterations can either be specified explicitly, or the model can be allowed to run until the values obtained from the STAR-CCM+ model have become relatively stable (i.e., the coupled model is converging). Code has been written for both methods of limiting the number of iterations. Lastly, the script component also sets the value of the mass flux of the slurry to the cold cap (MFEED) and passes this value into MATLAB. This value can thus be easily changed in ModelCenter when necessary.

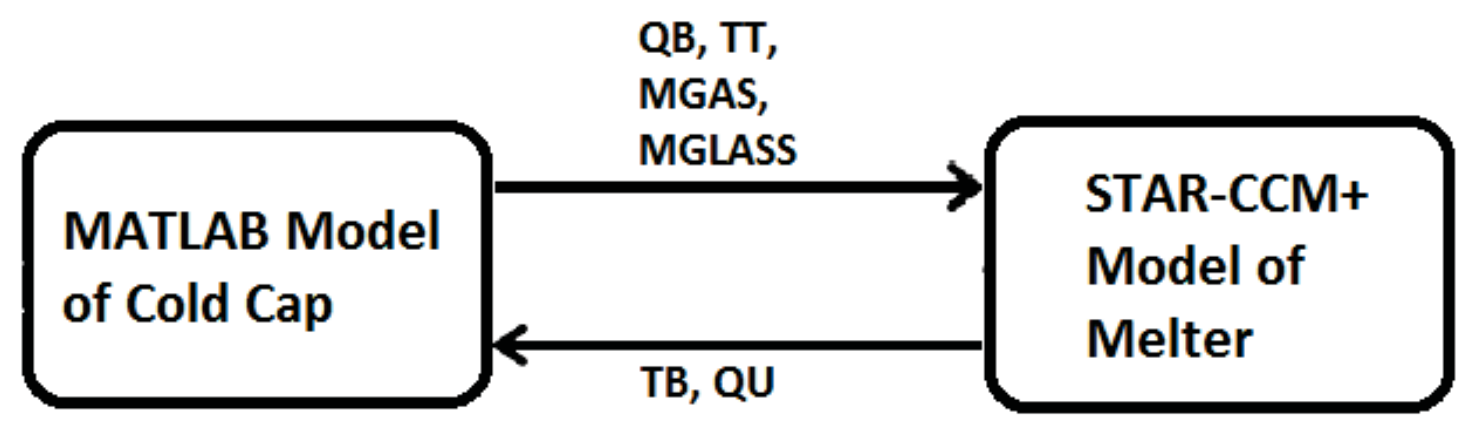

Figure 4. Outline of data exchange that occurs in coupled model.

In the implementation of the coupling, the original cold cap model ${ }^{2}$ has been amended to account for the information interchange that takes place between the two models. The original MATLAB model does not return outputs or accept inputs, and the coupling requires that the model return QB, TT, MGAS and MGLASS based on input values QU, TB and MFEED. Therefore, the cold cap model has been altered to allow for the calculation of required values based on the inputs. Perhaps the most significant alteration is the incorporation of QU in the calculation of QB, as the original model does not take QU into account whatsoever. The main file of the simulation has also been changed from a script to a function so that it can be called from ModelCenter with the necessary inputs and provide the outputs required by STAR-CCM+. Because of this change, several global variables have been added to the simulation files so that the main function can share variables with the other files.

An alternate programming-based coupling method was also attempted in Simulink, a graphical programming language in which parts of the system being modeled are represented as blocks, and the interactions between the system parts are represented as arrows. In this coupling approach, which is based on a similar coupling performed by $\mathrm{CD}$-adapco to simulate a heart artery, the two models communicate over sockets encoded in Java. A socket is an end-point of a connection between two programs running on the same network. Overall, it is clear that the software approach implemented in ModelCenter allows for significantly more functionality and usability than the programming approach implemented in Simulink. The Simulink coupling requires that all methods of data exchange between the two models be provided in the form of Java code, whereas no such programming is required of the user in ModelCenter. Additionally, altering the Simulink coupling is much more difficult and time-consuming than making changes to the ModelCenter simulation, as the Simulink model requires advanced programming skills whereas ModelCenter offers an extremely intuitive, user-friendly GUI for model construction. 


\section{CONCLUSION}

A simulation that couples a 3D STAR-CCM+ model of a melter with a 1D simulation of the cold cap is being developed. The coupled ModelCenter model represents a step forward in addressing cold cap behavior in melter simulations. In the future, the model's capabilities can be expanded through the use of ModelCenter's optimization and trade study capabilities, which will allow us to optimize quantities such as melting rate and glass quality.

Further improvements will have to be made to the simulation to more accurately predict and control melting properties. The 1D model of the cold cap, for instance, will have to be altered into a 2D or 3D code $^{2}$ which takes into account horizontal heat and material flows in addition to vertical flows. Additionally, the model of the cold cap can be made more accurate by differentiating between the material properties in the various regions of the foam layer - the primary foam layer, the cavity layer and the secondary foam layer. The current model only differentiates between the properties of the open porosity layer and the overall foam layer. The 3D STAR-CCM+ simulation of the melter can also be improved to take into account the heavy metal sludge that tends to settle at the bottom of the melter. This sludge is usually what limits the operational lifetime of melters. ${ }^{5}$ The melter simulation also needs to be modified to reflect the dimensions and geometry of actual experimental melters so that results from the coupled simulation can be benchmarked by experimental data.

The above improvements would be steps towards creating a more accurate glass melter model, which would contribute to minimizing both the cost and the lifetime of the waste cleanup process.

\section{REFERENCES}

1. Hanford Vit Plant, http://www.hanfordvitplant.com/, accessed July 29, 2013.

2. R. Pokorny and P.R. Hrma, "Mathematical Model of Cold Cap - Preliminary One-Dimensional Model Development," Pacific Northwest National Laboratory (2011).

3. P. Hrma et al., "Nuclear waste vitrification efficiency: Cold cap reactions," J. Non-Cryst. Solids (2012).

4. R. Pokorny et al., "Melting of glass batch: Model for multiple overlapping gas-evolving reactions," Thermochim. Acta (2012).

5. Werner Lutz, "Modeling the Behavior of Noble Metals During HLW Vitrification in the DM1200 Melter," Vitreous State Laboratory (2005). 